\title{
Study on Balanced Development of Compulsory Education and the Construction of Rural Teaching
}

\author{
An Cai \\ Nanchang Normal University, Jiangxi Nanchang 330032
}

Keywords: Rural compulsory education; Balanced development; Educational equity

\begin{abstract}
. promoting the balanced development of compulsory education and continuously improve the development level of compulsory education have not only become a major task in the development of compulsory education in our country, but also become a difficult problem in the basic education work which the government needs to be solved. Based on that, this article has very important theoretical and practical significance. This paper analyzed the current situation of rural compulsory education imbalance and its problems in detail, focusing on the ideological value, education policy, system and other three levels of rural compulsory education unbalanced development of the reasons for the analysis, combined with research results, making an in-depth study on the development of rural compulsory education in the context of balanced education and put forward some suggestions.
\end{abstract}

\section{Introduction}

Compulsory education is the basic guarantee for the right to education of children in appropriate age, is the foundation to improve the quality of the people and cultivate cross-century talent foundation project. It can be said that the balanced development of compulsory education is not only the inherent requirement of the nature of compulsory education, but also the legal function of the government, also the important measure of the construction of harmonious socialist society. Promoting the balanced development of compulsory education has become a major task of the development of compulsory education in China. Since the central government put forward to build a harmonious society, the problem of educational balance has attracted more and more attention from all walks of life. In this context, to promote the balanced development of rural compulsory education has become the current basic education work that needs to study and solve urgently. Through this study, this paper aims to analyze the problems in the balanced development of education, exploring the connotation and extension of balanced development of education, analyze the present situation, confusion, difficulties and problems of rural compulsory education, and build a scientific system of balanced development of compulsory education mechanism to make plans, to make a contribution to promote the balanced development of compulsory education.

This paper first defines the concept of balanced development of compulsory education, and briefly reviews and summarizes the relevant research on the balanced development of compulsory education both at home and abroad through comparative analysis, which is the basis and reference for the balanced development of rural compulsory education in China. This paper expounds the significance of the balanced development of rural compulsory education in China from four aspects: education fairness, new rural construction, implementing laws and regulations and economic and social development, and analyzes in detail the current situation and problems of rural compulsory education imbalance in China. Combined with the research results, rural compulsory education development strategy under the background of balanced education get an in-depth discussion, and put forward some countermeasures and suggestions.

\section{The Current Situation of Unbalanced Development of Rural Compulsory Education}

Because of a variety of reasons, the development of compulsory education in China still has a large gap between the region, there is a serious imbalance between the urban, rural areas, inter-school. 
Unequal Opportunity Access to Education. The economic situation of the family is different, resulting in unequal access to education. Parents of low-income migrant families have a low level of education, and some of their social needs, such that children to go school are easily overlooked, and because of poor family economic conditions, it is more difficult for them to develop students, who are sent to the schools with poor conditions, some even are simply out of school at home;

Uneven Allocation of Educational Resources. China's educational resources regional imbalance is mainly reflected that school conditions, education funding, education development level have a clear gap between eastern, middle and western regions, but also the great difference of school conditions in the same region of economically developed areas, underdeveloped areas and poor areas. In the eastern part of China, due to the high level of economic development, the financial support for compulsory education is relatively large, which provides better conditions for the development of compulsory education in the eastern region. The conditions of schools in the eastern region are better, and their average investment in education and school building have basically reached the advanced level of the developed countries.

\section{Analysis on the Factors of the Unbalanced Development of Rural Compulsory Education}

Society is a huge complex system consisting of political, economic, cultural, legal, religious, educational and other subsystems, each subsystem in the system has its own characteristics and functions, the subsystems interact with each other, forming a whole system. Education as a subsystem of the whole system of society, its existence and development have a close relationship with social systems, which is restricted and impacted by the factors of the various subsystems.

Ideas and Values. In our country's vast rural areas there are still this one-sided ideas of "reading is useless". Although the importance of education has been deeply rooted in out heart, but in the eyes of many rural parents, reading is far less important than making money. Some parents have their own "small abacus", the purpose of reading is to make money, and now the cost of reading is too high, and even admitted that after graduating from university, they may not be able to find a work with lot of money, so not as early as possible to drop out to work in the field. This one-sided idea seriously affected the rights and opportunities of children in rural areas to enjoy education on an equal footing. Not only that, some rural parents do not have "compulsory education" concept, in their view, their children select to go to school is their own thing, it is not their parent's responsibility and obligation to ask their children to attend to compulsory education, which is the cause that many students drop out of school. In China's development policy, long-term "economic development are above all else," the development of ideas requires all development to move closer to GDP.

Educational Policy. For a long time, China has formed a concept of development of "city as the center" , all for the city, starting from the perspective of urban development. Most public policies, including central and local policies are tending to improve urban development and urban living standards, but ignoring rural development. Education policy is part of our public policy, based on the development concept of "city as the center", is bound to cause the development of rural compulsory education in China is not balanced.

\section{Discussion on Countermeasures of Balanced Development of Rural Compulsory Education}

To achieve balanced development of China's rural compulsory education is a long-term task, in this dynamic development process, only adhere to the scientific development concept, establish a sound corresponding legal system for rural compulsory education development, improve the security mechanism for rural compulsory education development, make it clear that administrative responsibilities of rural compulsory education development, increase the development of rural compulsory education resources, strengthen the development of rural compulsory education information in order to achieve the balanced development of rural compulsory education as soon as possible.

Firmly Establish the Concept of Coordinated Development of Urban and Rural 
Compulsory Education. Formulate an index system for detecting the development of compulsory education in China. Through the measurement of the index system, regularly published test data on the balanced development of compulsory education, so that all the power related to the development of compulsory education can operate transparently. Therefore, as to the balanced development of rural compulsory education, we should establish a strong index system, using the data to reflect the balanced development of compulsory education as far as possible in China, and regularly using the data and indicators to reflect the actions of the local government in the balanced development of compulsory education, treating the relevant data and indicators as standard to test the official performance appraisal, making the government power open and transparent in order to strengthen the government's sense of responsibility.

Increase Investment of Resources to Ensure the Balanced Development of Compulsory Education. We should increase the financial investment in compulsory education, apply diversified and diversified channels to increase investment in compulsory education funds, and actively improve the education funding investment protection mechanism, on the basis of continually implementing the existing education funding policy, make a good education surcharge, local additional fees and people's education fund collection and management by the law, to ensure that education investment. At the same time actively encourage units and individuals to donate students to attract more private funds to invest in education, to solve the problem of inadequate education funding. For private primary schools and secondary schools, adopt a more flexible preferential policies. Gradually set up to the government financial allocation, supplemented by the collection of taxes for education, non-compulsory education students tuition fees, school industry income, social donations and other channels to raise funds for education system, to achieve education fair and just, and further promote social harmony.

Establish the Sharing Mechanism of Educational Resources. Establish and improve the system of inter-school cooperation and exchange, accelerate and promote the application of excellent education and teaching results and conversion speed. Advanced education and teaching ideas, advanced education and teaching methods, should be really applied to the practice of education and teaching and timely translated into education and teaching productivity, establishing and improving the inter-school cooperation and exchange mechanism. By promoting the excellent teaching reform results sharing, good education teaching experience and results should be expanded in a timely manner. It is a very effective way to promote the balanced development of compulsory education and to carry out inter-school communication and cooperation. Through the forum lectures, open teaching, staff exchange and other forms of information exchange, the excellent resources from cities can be shared with the rural schools, to remould rural areas and promote the balanced development of compulsory education.

\section{Summary}

In order to make the balanced development of rural compulsory education in an orderly manner, so that the goal of balanced development of rural compulsory education can be implemented, it is imperative to further clear its objectives, refine the program and determine the direction of efforts. At the national level, it is necessary to focus on the goal of balanced development of urban and rural areas. At the local level, it is necessary to focus on the goal of balanced development within the county level. At the county level, the objectives of balanced development of inter-school and urban need to clear, and brought into the economic and social development of the overall planning. The balanced development of rural compulsory education is the balance of teachers. Balanced development needs the funding support, balanced development of rural compulsory education need to further improve the rural compulsory education funding mechanism for the promotion of rural compulsory education to protect the balanced development. 


\section{References}

[1] Q.L Yang, Bottom Line Balance: An Explanation of the High-quality and Balanced Development of Compulsory Education[J]. Theory \& Practice of Education, 2010.

[2] H Chu, L.Gao , The Design of the Evaluation Indicators and Standards in the Balanced Development of Compulsory Education[J]. Research in Educational Development, 2010.

[3] H Liu, M Liu and D Lin, Original Balanced Development of Compulsory Education[J]. Journal of Northeast Normal University, 2005.

[4] W Chen, The Thinking of the Balanced Development of Compulsory Education in Qinghai Tibetan Nationality Area[J]. Journal of Qinghai Nationalities Institute, 2007.

[5] $\mathrm{T}$ Zeng, $\mathrm{Y}$ Deng and $\mathrm{R}$ Yang, et al. Balanced development of compulsory education: Cornerstone of education equity[J]. Frontiers of Education in China, 2007, 2(4):469-493.

[6] C Xiong, Supervisor D, Humanities D O, et al. On the Three Strategies of Connotative Balanced Development of Compulsory Education[J]. Educational Research, 2010.

[7] Center for Educational Policy Analysis of China National Institute for Educational Research. Balanced Development of Compulsory Education:The Cornerstone to Realize Educational Equity[J]. Educational Research, 2007.

[8] X.Z Fan, The Balanced Development of Compulsory Education and Breaking the Difficulties of Rural Education[J]. Journal of Huazhong Normal University, 2013.

[9] X.H Zhang, The Balanced Development of Compulsory Education in Rural Areas:Problems and Countermeasures[J]. Journal of Northwest Normal University, 2012, 7(7):e39821-e39821.

[10] L Hu, The Problem and Improvement of Educational Finance under the Balanced Development of Compulsory Education[J]. Research in Educational Development, 2011.

[11] An L U. Reflections on the Balanced Development of Compulsory Education[J]. Journal of Qingdao Technical College, 2011.

[12] Y Mei, On Decision-making and Benefit Expression in Balanced Development of Compulsory Education[J]. Onmorary Daon \& Lr, 2010. 